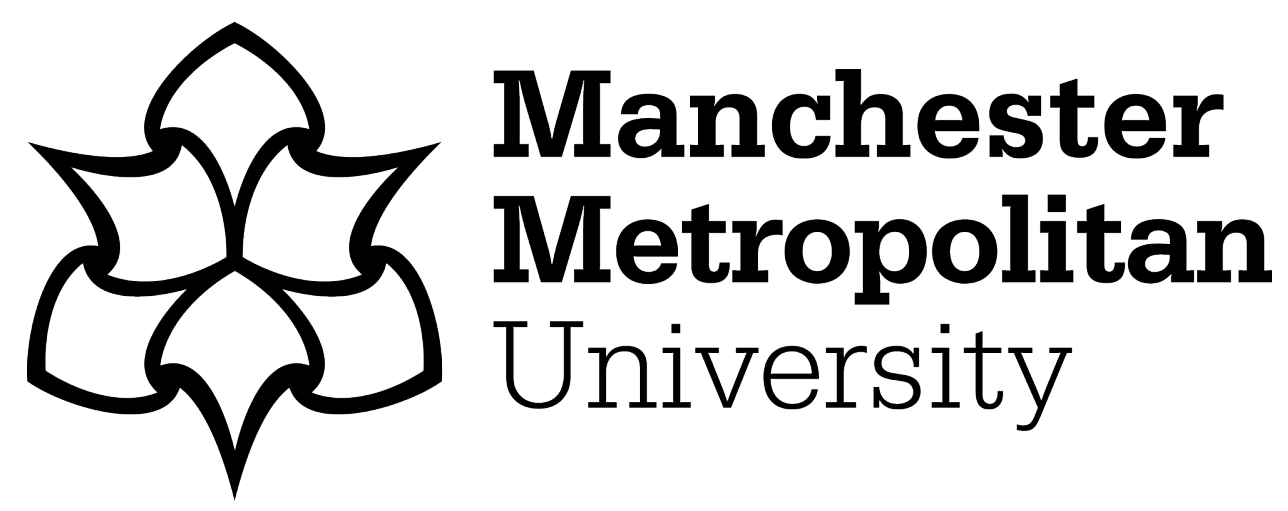

Cardoso, Daniel ORCID logoORCID: https://orcid.org/0000-0001-7864-7531 (2021) Interview with Meg-John Barker. Sexualities, 24 (8). pp. 1081-1099. ISSN 1363-4607

Downloaded from: https://e-space.mmu.ac.uk/626305/

Version: Accepted Version

Publisher: Sage

DOI: https://doi.org/10.1177/1363460720957206

Please cite the published version 


\section{Interview with Meg-John Barker}

Daniel: We've been talking about this for months so I'm just going to dive right in, but if there's anything you want to say at any point, if you wanna stop, just let me know. You're one of several people with an international research profile to leave academia in the past few years. Interviews like these often ask the interviewee to explain how or why they did it. But for one to exit a space, one needs to know what that space is, where it is, and evidently what are its borders. And so I think I prefer to ask first, what is academia? How do we define its borders and gates, and what does it mean to leave it when we leave so much of ourselves - and maybe you'll disagree - behind in the form of publications, ideas and so on.

Meg-John: The first part of your question makes me think there are so many stories we can tell through an experience in our lives. So if I must explain why I left academia I can think of three stories I could tell. One emphasises the problems with academic systems and structures, one is quite an individualistic story focused on the "me" part, and a further story about the mismatch between the two perhaps. So... yeah, I think there's something useful about not telling that one single explanatory story, and instead thinking about the stories I was called to tell about myself within academia that never felt very congruent: the stories you have to tell for promotion, for example.

It was really interesting because when I left academia I went for one of those voluntary severance schemes ${ }^{1}$, where they let you go and you get a lump sum. I'd always had to tell these stories in academia that were kind of like Nikolas Rose talks about in Governing the Soul (1990). You tell the narrative of your successful self: you always had a plan to be this kind of academic and you've been working towards it all of this time. But when I left academia, I had to tell a story where they'd want to let me go, basically.

So I had to tell a story where I was a liability, where I wasn't a great person to have around. And it's such a headfuck to go from telling this ongoing progress individualistic narrative which is incongruent in one way, but now I'm having to tell this other incongruent narrative that's like "I've made myself a liability and you wanna let me go from this institution".

\footnotetext{
${ }^{1}$ A voluntary severance scheme happens when an institution needs to lose staff. All staff are offered the opportunity to leave and given a lump sum on leaving. They and their managers need to make a case that it would be in the Institution's interest for them to leave.
} 
Going to the second part of what you're asking. Stuart Hall, the cultural theorist, apparently said that it was only on leaving academia he finally became an intellectual. And I think that speaks a bit to what is academia. Because I've really noticed since not being affiliated with a university anymore, I thirst more for scholarship and intellectual input than I did before. I actually feel that in a way I am reading more books and papers and theses, and I'm probably going to some more academic events than maybe I did before. But it's left me with a really different engagement with that stuff than I had before. I'm liberated to explore the forms of knowledge that I really want instead of feeling pressured to explore certain ones and not others.

So that kind of troubles what we mean by academic, or what we mean by intellectual. Is it about engaging with intellectual thoughts? In which case I'm still an academic. Is it about belonging to a specific kind of institution, the university? In which case I'm not.

But as you say, you left your mark now. Some academics draw on my work, on this body of work. As long as academics are drawing on that body of work does that mean I'm still an academic? But that body of work has always sat uncomfortably within academia, so then I'm not an academic. I could just keep going back and forward between "this means I am one", "this means I am not one", right?

D: I was just thinking that, maybe, looking at things from that perspective, the sentence "I left academia" or "I didn't leave academia" is overly simplistic because it brings everything down to just one focal point.

MJ: Yes, exactly, this one point in time feels really important, like this real turning point. And I think, like you were alluding to other intellectuals like Sara Ahmed, those turning points have been really important to us personally and politically. And they also perhaps become important to academia to notice that people are leaving in these particular ways.

But it's also this more Buddhist/constructionist notion that the self is much more like a flowing river and you can never get a bowl of water out of that river and look into that and see the river. That sense of self in process has been something that's always resonated with me. So to name a kind of end point, it doesn't make a lot of sense, like I was leaving for years, maybe I was always leaving, I was never comfortable there. Yeah, I've spent 20 years leaving academia! [both laugh]. No, 40, because my whole life I was always in education, then university, then $\mathrm{PhD}$, then working in academia so I literally haven't been out of education until last year. Always leaving. 
D: You mentioned Sara Ahmed (2016), who performed her leaving of academia in a very political way. Do you feel you've done something similar to that?

MJ: Not quite the same. Well, I guess this interview feels like an interesting space for me because it has given me the chance to do that kind of leaving academia thing publicly. It's going to be in a journal, wow! You know? I did blog at the time but it was a much wider blog about the concept of failure (Barker, 2019), which relates a bit to Jack Halberstam's work around The Queer Art of Failure (2011).

The sense was I went self-employed at the same time I was single for the first time, pretty much, as an adult, and living alone. I saw all those three things as happening simultaneously, the rug pulled out in terms of work, in terms of home, and in terms of conventional partner relationships. And in all three cases something I'd been working and writing towards for so long, but now actually living it. So that was the kind of public statement I was making: This is what happens when things fall apart in life. And all those failures were also successes, sort of questioning "what is failure anyway?" It was a really hard time but also really incredible, opening up space for me and my work.

But I haven't had the chance until now to do that reflection on the academic bit specifically. I did say a little bit in that post about some of the issues with academia, and tensions around it for me, but this feels like a chance to... yeah... [both laugh]. And I so wanna do it right, as well! I feel a kind of pressure. I don't want to just do a kind of dissing of all of academia. Like I have seen a lot since I've left, and during the process of leaving, that I feel very critical about, but I don't want it to just be this kind of dismissal of it all. I think there's reasons to be in the system trying to change it and there's reasons to come out of it and critique it from outside. And we can even question, as you have, this inside/outside binary. The author of Life isn't Binary is not gonna [both burst into laughter] reinstate an artificial binary. Just call me out if I do that!

D: Good! But now I'm curious, how does that narrative on failure sit next to the narrative on liability that you had to produce?

MJ: Oh, being a liability? Yeah! I guess partly what brought that failure stuff to mind was having to write that thing. And I was really well supported in it by my head of department... but I noticed the impact of writing this kind of piece. And again, what stories to tell through it? Because I'm a trans person writing on trans within academia at a time where there's a huge 
tension around trans - particularly in academia, and that work sometimes gets picked up by the media in negative ways. If I really want this lump sum, you know, do I bring those things into it or not? But what does that do to me if I do? To say that these are bad things about me, or at least bad things for the institution.

And the institution actually said "you absolutely can't use being trans as a reason why we should let you go", you know? [laughs] And rightly so, they absolutely shouldn't be able to use that. But it's interesting to note the shift, when being openly polyamorous and writing about that was something that I was told in the past nearly got me fired for "bringing the university into disrepute" because of how media responded to that work $^{2}$.

It's also complicated what telling that story does to you because I remember telling the success story left me with a bad taste in my mouth. And the failure story also left a bad taste. It's like, how can we enable people to tell much more complex and multiple stories? And hold them all together rather than having to tell these individualistic narratives that are either good or bad, you know? Again I get that from engaging with Buddhist philosophy. There's this real question around those kinds of binaries, of what is good and bad: what is failure or success, loss or gain, fame or disgrace, praise or blame? All those kinds of binaries get called into question, but in this situation you have to tell this particular narrative of it always leading to success or always heading into failure. What does that do to us?

So in the piece that I wrote about failure, I was thinking about failure in relation to relationships, home, and work. And what I noticed was that having gone single, having had a couple of breakups, just how full of love my life was. I was having conversations about how difficult love was with all my close people, which were actually an act of love in themselves and bringing me closer to those people. So it's this kind of paradox of love coming out of the loss of love. And then I thought a similar thing is happening with home, you know? I'm getting more of a sense of at-homeness, having done these multiple moves in quick succession. I've lost houses, but gained a sense of at-homeness in myself and in the environment where I ended up living.

\footnotetext{
${ }^{2}$ In 2005, Meg-John Barker made the headlines of some national newspapers for presenting a paper on polyamory at a conference. Tabloid press, in particular, used this for sensationalist headlines, with the The Sun choosing the headline "Bisexual Boffin: I'm a Slut" (April 4, 2005); but even The Times Higher Education Supplement published readers' letters where Barker was described as having a "troublingly authoritarian cast of mind", and being a "well-meaning ideologue [who] can often do as much harm as any number of lascivious male lecturers" (“Liberal Censorship?", January 21, 2005).
} 
And then I was questioning, you know, is it similar with work? Is the loss of work the work, in a sense? And I guess I'm framing the work as the emotional work here. And I think that became my work through this big transition period. So I also saw it that as failing at work and losing employment was also a great success in doing a very different kind of work and in prioritizing that different kind of work. And then again there was this paradox that so much of what I ended up writing and talking with people about in a work context became that work. As an (anti) selfhelp author I say that is my manure. That is the manure by which I grow stuff. So going through it became the work. It became both emotional work and the creative work. So yeah, I just really enjoy the paradox of all these failures also being successes at the same time: the pain also being the pleasure. Very non-binary.

D: And I think this ties very neatly with your work on plural selves (Barker, 2020). Could you please first maybe explain a bit more what you mean by plural selves, and then if you want to explain which of your plural selves - because I'm imagining a round table conversation - were involved in this decision and how each of those selves was involved?

MJ: Yeah, definitely. It's the idea that as well as being a process of becoming that we can tell multiple stories through, we can also see ourselves as being plural rather than singular.

The idea comes from a number of different places, really, but I've particularly engaged with some psychotherapists who write about the value of seeing one's self as plural. John Rowan in the UK, Hal and Sidra Stone in the US. There's also internal family systems theory which has that concept, and quite a few of the different therapists actually have that sense that we could usefully see ourselves as a system rather than a singular unit.

The idea is that the more that we can, first of all, identify the different parts or alters or selves or whatever language you want to use, and the more we can improve communication between them, the better for us and for everybody around us. Because if we are shutting off parts of ourselves then we're in a sense less whole, or we have access to fewer attributes that are within us. And also we can easily hurt other people with these disowned selves: projecting them onto them, having them leak out, that kind of thing.

So the whole concept of having an inner child or inner parent or an inner critic is a mainstream understanding of this plurality. Or just saying 'a part of me feels...' What's interesting, at the same time, is that this kind of therapeutic understanding has been around but there's also increasingly a movement of mental health survivors/mad pride to reclaim 'dissociative identity 
disorder': the psychiatric terms for someone who experiences themselves as a system of multiple people. And they're making these really interesting points - the people who are reclaiming that. You know, again that this could be quite a positive way of experiencing yourself that doesn't necessarily need to be a bad thing. It might be related to trauma that we fragment into different parts, and recognising that and communicating between those parts is very helpful.

I have quite a vivid sense of myself as seven different parts. [laughs] And that's been an ongoing process these last few years, me doing a great deal of emotional and creative work around this sense of plurality. It feels incredibly creative to me and it's a really rich experience, and it one that resonates with a lot of people. I think it resonates with a queer understanding of self, you know? And again, Nikolas Rose, who I was mentioning, I think would also see this singular individualistic neoliberal capitalist narrative of the self as being the thing that's actually mad. Perhaps sane is to recognize that we are constantly in process and that we have different aspects to ourselves. Also we're interdependent with others, so different aspects will be drawn out in different relationships. So it kinda fits with a intersectional feminist view as well.

How did that work with my decision to leave academia? I think there was definitely an element of "ok, what sides of myself had to be foregrounded within academia and what sides had to be disowned in order to succeed or survive there?" And there's been a sense of trying to rebalance.

So one aspect that has to be foregrounded, if you're gonna make it as an academic, is doing rather than being. You know? You have to produce these certain things in order to remain in academia. There isn't much value on just being. And the movement towards slow academia, I guess, is trying to go in that direction. But mostly neoliberal academia requires us to produce and to be very doing rather than being.

And then I guess these are all binaries [laughs], head rather body, it's all very much intellectual knowledge rather than embodied feeling. I suppose that moves towards affect theory are trying to gesture in a way of bringing the body more, but even theories of embodiment and affect are still about understanding in quite a heady way. That certainly ties in with attempts to decolonise the curriculum: to think critically about which theorists and theories are valued and where those come from. 
And I think to survive in academia it's also hard to be vulnerable and open. So more child parts of the self, and more 'just being' parts of the self, and more body focused, and slower rather than faster parts, all of those felt less welcome. There were these parts of me that were really rewarded in academia, but these other parts that didn't seem to fit.

And I think going self-employed has helped me to rebalance that, such that I can see myself as having seven plural parts that all have an equal role. It's very much like trying to be a communal collective rather than the hierarchical system. Most of my life one or two parts have been foregrounded and the rest have been very much pushed down, and now I'm trying to address that balance a bit. And I think that's a lot easier outside of academia than it would have been within. I struggled with those moments in the last few years of being in universities where I became quite vulnerable or child-like in academic spaces and then had a feeling like "oh wow, do I exist here?" This is not a part of me that's really welcome here.

D: Weren't the parts of you that were foregrounded trying to push back against you leaving?

MJ: Yeah, yeah, and I think that's again why the plural selves ideas were so helpful, because it brings them into communication. You can kind of have a useful way of understanding how when you feel conflicted there are maybe two or more parts of you pulling in opposite directions. The part of you that wants to be seen as a successful person within a particular field is going to be pulling in one direction, and the parts of you that want to bum around, or rage against the system, or are hurt by the system, are gonna be pulling in another.

I definitely noticed when I left, there was a part of me feeling like "wow, what even am I now?", a real identity crisis sort of moment. And almost like a big hypochondria wave of "do I get a horrible illness and die now?" That really came up. I don't have those sort of health fears usually, but in the months after I left I had a lot of that. And I wonder if that's a part of me almost not being able to quite compute that I get to exist free of employment, almost couldn't quite handle that.

There's also a question of what validates you. Having been in education my entire life, there's never been a point where I wasn't getting grades or papers accepted or rejected. I'd been so institutionalized into "this is how you determine your value" and so what am I left with? I was liberated in a sense of determining my value however I wanted to determine it. But... outside of that system what are the markers? And I think I'm still in a long process of learning to let go, surrender some of those markers and co-create different ones with the people around me 
and the systems I'm in now. Because you can't step out of culture, you can't step outside the systems entirely. But what systems do I wanna be part of, and what values of success do those have? It's nice to be able to navigate that, but it's also quite precarious.

D: You just reminded me of Ulrich Beck's (1992) take on risk society and how every one of us is sort of imbued with this obligation to manage risk, especially financial risk. Do you feel like this idea of making a risky move was a big factor in how you weighed the pros and cons?

MJ: Yeah, there was a lot of fear. It's really interesting what's come up as health anxieties and financial anxieties but rooted in shame. There was a sense of: people are gonna see this as risky, maybe it is too risky. Am I gonna get put back into a place of self-blame if things go wrong? That kind of victim blame view - you brought this on yourself - has come up. And you've gone against normativity as well, again back to the Queer Art of Failure. Like I've done this downsizing significantly so it's really away from that sense of you should be getting more and more money over time and buying bigger and bigger property or whatever, you know? It's like I'm going in the opposite direction: not building a conventional family, I'm much more building systems of support with other people who are on similar incomes to me now. And that feels really exciting to me, to be thinking very differently about family and community and systems and structures of mutual support. Like I'm getting to really live a lot of the things that I've often been writing about by doing life in quite a different way. And if you fail at it then you will be blamed for having stepped off that escalator or whatever.

D: You mentioned slow academia, and yet I see slow academia as another risk management strategy. Because you're trying to be more soulful but still not having to quit your job.

MJ: Oh yeah, good way of saying that!

D: But at the same time, and maybe this is just me being too cynical, I see quite a lot of people writing about slow academia, and it turning into a sort of rhetorical trope that exists only in an imaginary plane. I don't see people doing slow academia.

MJ: I don't know how you could, because I'm increasingly feeling that we can't make changes without systems and structures to support them. You can't, as this neo-liberal individual, start living your life in this completely different way unless you engage with different systems and structures of support. 
I don't think that any of the academic institutions would ever support genuine consensual relating to yourself: a slowing down, being rather doing, type of focus... It's not there in neoliberal capitalist university, it can't support that! So yeah, I guess this is one of the reasons why I quit, because those of us who are in these disciplines where we're critiquing those forms of capitalism, and we're writing these books about it, we're coming up with slow academia or whatever. But we simply cannot live it, there's just absolutely no way we can live that within those systems and structures, we would have to co-create very different systems and structures. It's something Rosalind Gill (2009) has written very well about of course.

It reminds me of the issues around consent in education. You can go into schools and teach these one-off lessons on consent and it's gonna do nothing because the entire school is nonconsensual, that's how it's set up. If we really want to teach kids how to be consensual, we have to change all the systems and structures to support a consensual way of relating to yourself and others. And that's kinda how I feel with this as well. You can't do much if the systems and structures are all set up to support a kind of fast non-self-consensual academia. And that's the reason why we see it kinda constantly replicated: Who gets into the positions of power in academia. You know, all of the systems self-replicate. And I think that was a lot of why I felt I had to pull back from it. Really noticing it...

One thing that's really hit me since I moved out is assessment. I've literally spent my life grading papers, but we're assessing privilege. We're assessing privilege when we give those grades. That's it. [both laugh] Took me a long time to see it! And once you do see it, it feels really queasy to give any kind of grades to anyone, right? You know? Who is being taught how to do a good essay or how to do a good exam? And who isn't given that support in their life, so it's always going to be terrifying?

And I guess I see it with colleagues as well, the people who are able to churn out paper after paper that hits all the right notes, or do the funding bits, are a certain kind of person. The people who are blocked by a massive sense of impostor syndrome really not believing they're good enough, or who struggle to ever learn those rules, are another kind of person, and privilege is a massive part of that. It hit me about vivas too. So many marginalised people are trained our whole lives never to question those in authority, to just accept any criticism because the whole world says that person and their ideas are more valuable than yours are, even that defending yourself with an authority figure can actively put you in danger. And then being called to 'defend' your work in a viva! It's not a level playing field when some people have been trained 
that everything they say and do has value and how to defend it, and another group have been trained in the exact opposite, and that is engraved through our bodies and brains. Similar with having a paper reviewed. Such a massively different experience for different people by gender, by race, by class, by disability, etc.

D: I wonder if we aren't creating another guilt-tripping fast-track with this slow academia thing?

MJ: This is very much the critique that I've been engaged with for many years with the mindfulness movement. Mindfulness in the West frequently becomes another stick to beat ourselves with. So we're told we should be being rather than doing, we should be slowing down and we should be practising meditation, we should be living our lives in these really different ways. And all that Western audiences do is then give themselves a hard time for not being a good neoliberal capitalist citizen and for not being good at mindfulness. And all of this means we take our eyes off the ball of any kind of political engagement because we're so busy beating ourselves up that we're now crap twice over.

Slow academia risks doing exactly that. Now you've got another reason to feel bad about yourself, you're not doing enough self-care, you're not slowing down enough. And the ideal image that we all have in mind then is this amazing professor who is able to churn out these papers and get all this funding while still being slowed down. And the system doesn't support that in any way! Certainly only people who are very privileged and well-supported within academia and within their wider lives have any possibility to be that. Over the years, academics have been expected to do more and more and more and more. The system does not support you in becoming a slow academic.

D: When you're publicly a trans person, people will always go on to the gendered dimension of whatever you do and I think it becomes sort of a fixture question. But, at the same time, we know that academia is really gendered. And so, because you did not always present in the same way, and because you have a very public narrative of navigating different spaces while presenting differently, what's your take on that? How would you sum up the gendering of your trip in academia in regard to that?

MJ: Ugh, [sighs] it feels like gender is massive for me through the whole experience of education. I was presenting as a woman through my early days in academia and I just really noticed the difference between the guys in my peer group and how they were being treated and 
me. Again, it's a hard one, because you can't know where people were coming from, but I really struggled to find any mentorship. And I certainly noticed with supervisors often them spending a lot more time with male peers, having different relationships with them, which was maybe understandable because they maybe couldn't have had that relationship with a female mentee. You know, the ways that it would have been seen or whatever, but what it all leads to is fear; I never had someone take me by the hand, show me the ropes in the same way as a lot of my male colleagues did.

And when I spoke out about various things it was read in certain ways because it came from somebody being read as a woman. And I just often had this sense of, had it been a man saying those things, that might well have been applauded, whereas it was seen as really problematic coming from me. Certainly the ways I was put down for things I spoke out about was very gendered. Interesting, mentioning Sara Ahmed, it was back in 2004 or 2005, when I wrote a piece for the Times Higher Educational Supplement about how common it was for male academics, particularly older ones, to be preying on female students. You know, I'd been in so many institutions where this had just happened and everyone would just laugh it off, but I'd seen a lot of female students leave because they'd had such awful experiences with these male academics who were literally looking at the newcomers as fresh meat every year. When I wrote about that, the response in the letter page was incredibly gendered in terms of how I was positioned. It was kind of a slut shaming response of me, basically, that was the way I was undermined for having said that.

\section{D: Which kind of proves the point... [both laugh]}

MJ: Exactly! So yeah, there's a lot of grief for me about those years in which I was presenting as a woman and navigating academia and it felt like quite a lot of being slapped down as a silly girl, to be honest. These responses, they felt very painful, you know? I remember being given these lectures from older male academics about how I'd stepped out of line and seeing male colleagues who had done similar things and been applauded, and there was a sense of "who knows those rules and who doesn't? Who gets to break them and who doesn't?" And also that thing in the meeting where I say something and it's ignored and then a guy says the exact same thing and it's celebrated... Women being expected to do a lot more emotional labour, being expected to do so much on top of their paid work, being seen as 'hard-working' rather than smart. It's not specific to academia, but I definitely really felt it. 
And then, on being trans and being in academia, again not specific to academic spaces, but just people not getting it and thinking it was ok to not get it. I had colleagues who up until the end weren't using my pronouns and they didn't really feel that it was a problem. One who refused to use my name, just kept using my old name and every time I mentioned it just kind of ignoring it.

And then, in most of the universities in the UK at the moment there are people who define as 'gender critical feminists' in professorial positions. Universities generally respond by naming it as a feminist infight, and we're not going to take sides, so actually kind of supporting that that's ok for those feminists to make very transphobic statements, to claim that trans people aren't the gender they say they are, or that they are crazy or abusive. And that doesn't feel like a safe place to be, so I was quite glad to be out of that and not have to keep having those battles. Quite often universities respond by saying “oh we'll have a panel and we'll put both sides on the panel", and you're just not able to get into the "well, it's not really two sides when one person is saying another person doesn't exist or isn't legitimate in their own identity". And I don't want to spend my time fighting gender critical feminists, it's not of interest to me. But it's almost like you have to if you're gonna remain in those systems as a trans academic at the moment.

Ruth Pearce (2020) recently wrote about all this very powerfully: about what it's like to be under constant attack as a trans person, to watch our friends literally dying, sometimes to feel like dying ourselves, to hear it from our research participants, and to have to face this lack of support in our institutions, and the implicit rules against vulnerability in academia when that is our lives.

D: A lot of those (anti-trans) academics are actually women, so it's not just the old 'men vs women in academia', it's a lot more complex than that.

MJ: Yeah, it's really complex. I've got a lot of thoughts on what that's all about [both laugh]. And it's generational as well. There's a real sadness and grief around it being a within feminism battle and a within LGBTQIA+ battle. I don't want to be battling within feminism or within LGBTQIA+. I want to be fighting collectively alongside about systems and structures that do need to change. So it's quite nice to be away from all of that. If you're in the university where that is happening all the time, then all of your attention can easily be drawn in that direction 
D: Maria do Mar Pereira, in Power, Knowledge and Feminist Scholarship (2017), talks about how back office chatter sort of feeds into who gets promoted, hired, and even who gets to have some mental health space within the institutions. Was that a part of your experience in academia, and was that a part of your internal process in deciding to leave academia?

MJ: Yeah, I mean certainly around the time that the really hard stuff happened for me, a big part of why it was so hard it was that there was quite a bullying culture there already, which I'd kinda unwittingly fallen into. I didn't know that it was there but I heard later that in that department at the time bullying was happening and almost that people would be relieved when the bullying came off them and onto the new person which was me [laughs]. So I was bullied in that department, but it was quite under the radar stuff, so it was gaslighty, you know, like you knew something was going on, but you knew there was nothing you could pin it on. I remember trying to make a complaint and realizing I just didn't have any evidence for it, but I knew that it was happening.

And then when the press reported around my polyamory research, it was blamed on me and I just bought it, you know? It was like I've done this terrible thing and I just have to make up for it, kinda knuckled down and make myself the best possible colleague, that was how I dealt with it, which was also how I dealt with bullying at school: I tried to turn myself into the person who wouldn't get bullied. But at what cost, you know? I think that took a really big toll. I look back on that time and I really question the decision that I made to stay at that point. I wonder what my life would have been like if I'd said “it isn't ok to be treated this way" and I'd left.

So I think in a way my decision to leave now is almost a little bit on behalf of that person back then, like I'm finally saying no to this. Even though I ended up in a really good situation and a very supportive institution and department with a lot of friends. Still, stepping away feels a bit like I'm giving something to that version of me that decided to stay in a really toxic situation.

So yeah, I feel like the corridor and coffee break chatter, like you said, for me just brought up a wave of like "yes, I remember what that was like" when I was hearing my name in a corridor, you know? And I ended up quite paranoid, 'cause I knew stuff was going on behind my back and people were saying things and I just never knew quite what it was or how bad it was gonna get, whether it was gonna get worse.

I remember being part of the Psychology of Sexuality section of the British Psychological Society. They were an incredibly supportive group for me when I first moved to London and 
was starting out as an academic. And a group of lesbians within that group had set up quite explicitly, for quite a few years by that point, a kind of network where they would deliberately cite each other's work and support each other because that was necessary for them to get any kind of recognition, and they were trying to balance something out. And I remember feeling, as a bisexual person, like I wasn't part of that. So there were the men who were doing that and being a bit of an all-boys network, and then these feminist academics had come up with their own way of fighting that by really supporting each other and citing each other, and then what about me? And the even queerer individuals? [laughs] We didn't have that kind of thing.

And I suppose it makes me think of Audre Lorde's 'The Master's Tools...' (2018) kind of idea. You know? I could have stayed within academia and played that game and co-created my own queer network where we'll cite each other, and maybe I kind of was, to some extent. I certainly went out of my way to support academics like yourself and like some of the people whose PhD's I'd examined, I tried to become this kind of mentor for them... But yeah, to what extent is that perpetuating the same kind of systems of injustice, you know? Who do I end up supporting and who do I not end up supporting? It just brings me back to that idea of 'The Master's Tools...', it's like... it could so easily be I'm that next wave supporting these younger queer academics, but I'm leaving out others. Perhaps most of them are white, or of the same educational background as me. And still there are people who are excluded from that, and it still perpetuates this idea that you have to do that, in order to play this game and lift certain people up.

The whole system needs to change, rather than this trying to find ways to game the system. So I guess that's the question so many of us are asking now, all the time: how do we change these unjust systems when we see how utterly unjust they are? All of these systems: the criminal justice system, the education system, everything. How can we do that? Because complete collapse is gonna hurt people, but when trying to change them from within you so easily end up reproducing the very kinds of issues that you were trying to change. I noticed in academia that the more power people got, the more they ended up seemingly part of that system and reproducing it. It's so hard for people to reach a position of power and still be really challenging it. You get kinda wrapped into it somehow and you can't see some of the stuff that you were seeing when you were more junior. In being given power by that institution you kinda want to buy into the discourse that says that you're a just recipient of that power, do you know what I mean? 
D: Part of that interpersonal dimension of academic existence has been the subject of blog posts you've recently written, especially about pedestaling. As we have spoken about, between ourselves, I'm also fully responsible of doing that to you. I can remember being part of a panel with you, with Christian Klesse and Jamie Heckert at the Sexual Cultures Conference, back in 2012, and I remember seeing you in the hallway of the conference and beaming up at you and being besides myself with talking to you... In awe of everything that was happening. Which is basically most if not all of the markers that you identify [both laugh] as pedestaling. So how did the phenomenon of pedestaling impact your work and mental health? How did it transform your theoretical thinking, and especially the way you perceive academia?

MJ: I did my therapy training in existential therapy, so reading a lot of Simone de Beauvoir made me think about this thing of objectifying people and what that does. Being a writer and realizing some people were treating me in certain ways as a writer, this sense of people kinda looking up to you but not really seeing you as a fellow human being at all, you're that person and the sort of expectation that comes with it. And this real sense of, if you're up on a pedestal you're going to fall off. And it's gonna really hurt! And I suppose that happened a few times in different ways and it really impacted me that there's an unrealistic expectation of what I would be like. You have to maybe disown your more vulnerable parts and only project your bulletproof and strong parts, and that's doing a violence to yourself, that is kind of severing you.

Again, we're part of this culture that is non-consensual, is racist, is sexist, homophobic, biphobic, transphobic... we're gonna replicate that. You know, this is what a lot of the recent anti-racist stuff has been pointing out, is that under structural racism, we're all gonna be racist. And I think that in a non-consensual culture, we're all gonna act non-consensually sometimes. And so anyone who's pedestalized is just gonna fall off because they're gonna do these things, you know? I try really really hard to be as up on everything as I possibly can be, and to act as ethically as I possibly can, and I'm gonna fuck up time and time again. It's just inevitable. And I think it's just really frightening to be on that pedestal knowing that I can fall in that person's eyes. And given, again, the background that I've had, of a lot of bullying and shame at school and then again later in life, it's easy for me to go to a shame place.

So I suppose the first few times people treated me that way it was like, that "Oh! You're MJ Barker", and I would be like "yeah!", you know? That feels really great! Like a bit of validation, and then the more time went on I realized it was the flip side of being cast into shame when I 
let somebody down, or they perceived me as having let them down, and I realized that I would far more rather be seen as this whole human being in the first place.

It's complicated because it's amazing to be respected, and feel that people have a fondness for you because they love your words, you know? Particularly when people see my books as kind and friendly, that feels really moving to me because that's what I'm trying to be, or when people find my ideas exciting and I get this kind of reflection of, you know, that this weird path that I've chosen to follow has resonated with other people, like that's what it's all about! That connection! But I suppose that's a bit of a different thing to pedestalizing. I feel like I've connected with somebody and we're part of this much bigger conversation and I've been part of a conversation that's been useful to them. That feels amazing! But that comes from a slightly different place.

It makes me think of Erich Fromm's ideas about having and being. Having is all about fixing somebody and objectifying somebody, whereas being is like this kind of being alongside and being present with. And maybe that's where our relationship has shifted, you know? Obviously when we first met we didn't really know each other so it'd be easy for us to see what might this person be for me and to objectify. But as we've known each other, hopefully we've got to know more and more of each other and that feels like more of a being kind of relationship. And I suppose that's what feels like a comfortable relationship to me where I feel like I can bring all of myself and hopefully the other person can bring as much of themselves as possible as well.

But again, like the example you gave, I'm sure that there was some of that from my side as well because as I said, having felt quite under-respected, in a way, throughout academia. When I got to that certain point where I was meeting more junior academics because I was now a bit more senior and some of them were being "wow" they really liked the stuff I was doing. That gave me a lot, actually, to have a few people of, I guess of your generation. It felt like that was where I was getting that kind of recognition from, it was rarely from my peers, and it was rarely from older academics, with the exception of some people like Rosalind Gill and others in the Psychology of Women community which meant the world to me. It was mainly from people of your generation, who were saying "actually, I've been drawing on your work" and... It really did feel great to have that recognition. So it's about the nature of the look, isn't it? Is it a look of pedestalizing and objectification, or is it a look of really being seen? And I think we all really want to be seen. And it's wonderful when somebody really sees us, and what they see is that 
potential, or what we've done, or what we've given. But maybe it's not always easy to tell the difference between the two.

D: But academia also has its very specific interpersonal hardships. I'm thinking about coauthorships, citations, journal indexes. How did you navigate that, and how much of the act of navigating that minefield was then part of the reasons why you wanted to leave?

MJ: Somewhat I could see the game and didn't really wanna play it, and somewhat I was drawn into it because I knew that you had to play the game to some extent. One way I navigated it was, I kept trying to point out to people that academics just can't do all of these things. Fortunately, in recent years people in my institution were really pleased that I was a public academic and that I was doing these public facing books. I was really supported in that, which was wonderful. But it was still expected that I would go for funding bids, publish academic papers, do research, do teaching, do admin, take on more and more and more managerial roles... and I would just keep saying it is impossible for anyone to do all these things. If you want me to be a public academic then that's what I'm gonna have to be, and it'll mean I'll publish less papers, I won't get funding, you know... Why not let people do what they find most fulfilling and are most skilled at? Because there was also a pressure on a lot of my colleagues to be public and to go on social media, when they had zero talent in that direction and hated it. Why try and make them? Let me do that! They could do the other thing! It never seemed to go down well, and it just seemed so simple and straightforward to me, just a matter of fact that people simply can't do all of these things.

And then the other thing, I suppose I would say, is that I kept trying to tick the boxes, you know? I kept trying to figure out what was that REFable paper that I could publish, and I don't think I ever published a REFable paper, I never got included in a REF anyway despite publishing well over a hundred books, chapters and papers. Because it seemed like the goalposts kept changing! I'd finally get a paper in a journal that was research based, but then the journal wouldn't be high impact enough for them. I'd finally get a journal paper in a high impact one, but then it wouldn't be a research-based paper. Or then somebody once told me that something didn't count because it would be better to have a single author paper than to have co-authored it, or you know, like a special issue didn't count and a regular journal issue did? [laughs] Every time I'd try to publish something there would be some kind of response like that that I would be a bit baffled by. 
The first time I tried to publish in Sexualities was a case in point. So Sexualities, years and years ago, was doing this special issue about Gayle Rubin, so I put in a paper which I thought was a similar style to Thinking Sex (2007), you know. It was a bit of a 'where are we now in some of these things?' And it got rejected for being too polemic. And I was like "hum, but Gayle Rubin.... Have you read Thinking Sex?" [both laugh] I'm responding to a polemic paper in a polemic style and I'm being rejected for it! Always stuff like that! It just didn't ever really... What are these things I need? I need to get published, and then what? Even once I was getting published, to get published in the right kind of way, it was always a moving target. And I suppose it was painful at times, the rejections, or the realizing that even though I had been published it didn't count, and I was spending all summer, every summer, writing freaking academic papers when I could have been having fun, and none of them counted, so I do feel like a little bit of grief about that! [laughs]About how much time I spent chasing this invisible unicorn! [both laugh] ...of trying to be REFable, to be excellent!

So yeah, it doesn't feel possible to completely let that stuff go, for me anyway, within a system. I got as close as possible to not caring about that stuff, even while I was still in it. But it's really hard to completely not care when you're being told "this is what is valuable". So I must say it feels one of the biggest reliefs of being outside of it, is that no one gives a damn about academic journals. Do you know what? I'm going to be published in three academic journals this year though... [both laugh] That's ridiculous! Three academic journals have got in touch with me including this one - saying "can we do this interview?" "Please would you write something about comics for us?" I'm actually now going to have three academic publications in the year I left academia, that is hilarious! [both laugh]

D: That points towards a split between academic research and the public intellectual, so to speak. And you're sort of now in the second position...

\section{MJ: Yeah! [chuckles]}

D: And, you know me being me, Foucault says there's no power without resistance, right? So would you consider yourself to now be performing this work of resistance? And if so, how would you describe what you do now, and do you perceive what you do now as being resistive vis-a-vis academia and the academic world?

MJ: I'm always going back to that simple question of, what do you find most fulfilling and what are you skilled at? And I think in answering that question when I was within academia, 
and still now, I feel like what I find most fulfilling and what I'm best at is taking all of these ideas and synthesizing them for the general audience. What has always motivated me is getting the ideas and research that resonates with me out to people who need it.

When I looked at the self-help section of the book shop when I was younger, when I was trying to figure myself out and help myself, there was nothing useful. There was Mars and Venus, you know? [laughs] And then I went to university and I'm learning all this stuff that actually feels genuinely useful, and then I'm getting involved with activism, and then I'm training as a therapist. I'm learning all these things which feel actually, potentially, incredibly helpful. They're not making their way out to people, you know? For example, theories of gender that I find incredibly helpful are not generally finding their way to an everyday audience.

So, in some ways, that hasn't changed that much inside or outside academia. Those academic ideas and theories and pieces of research are still things that I really want to get out to a general audience, but I just want them mixed up with the stuff that I've learned from activism, from therapy, from spiritual practice, you know, from my lived experience. And I want to get them out there in multiple formats too, that people engage with: comic books, podcasts, blogposts, zines, self-help books.

D: Yeah. I thought of resistance because it feels like, in a way, you're fulfilling at least one or several of the academic functions, but outside of academia. You're resisting the academic institution by doing academia outside of academia.

MJ: Yeah, yeah, yeah! And I do feel this funny sense of being liberated to do it even more so.

D: And you mentioned that you read more now, that you're gonna publish more now...

MJ: I think so! It's ironic! I guess there's a certain resistance as well, in insisting that I will bring together the ideas and practices that feel valuable regardless of where they come from. I don't mind if I've heard them in a café or if I read them in Judith Butler, it doesn't matter to me. It's like, let's bring it all together, particularly this sense that...it's a key idea in Buddhism and in intersectional feminism as well, actually, that the knowledges we get from reflecting deeply on our experiences can be as valuable as those from a research project or whatever, and that definitely resonates for me. Quite a lot of things you can get them intellectually, but it's only when you live through them, embody them, and you're like "oh god, that's what it feels like to be misrepresented" or "that's what it feels like to notice how culture occupies the body" 
or whatever. I think I always want to at least equally value the kind of outside and inside wisdom.

D: I've got a sort of a provocation question now.

MJ: [laughs] Yeah, go for it!

D: In a way, this idea of self-employment can be construed as the pinnacle of the neoliberal subject.

MJ: [laughs] Probably!

D: How do you sit with that?

MJ: Yeah... I'm gonna sit with it for a moment. [both laugh] That's where I'm gonna start sitting with it: by sitting with it! [pauses]

I suppose I'm driven by wanting to live life differently. And what that involves for me at the moment is wanting to really work with others to find ways to create microcultures and systems that are kind of interdependent and involve mutual care, like really different ways of living and relating and working. So the move I've made to something that looks much more, like you say, in a sense, much more individualistic, is partly a move towards trying to do the work that I need to do in order to operate in a very different way. I felt like within that kind of employment, there was just not the space or the resistance necessary to do these things in a radically different way. And that requires self-practices: a kind of intersectional feminist self-care or a kind of Buddhist spiritual practice which is all about how we're interconnected and interdependent, so it's not about this different separate self. I feel like I need to do a lot of that kind of work, to balance the other kind of work that I've done. [both laugh] To become somebody who can experience myself, my selves [both laugh], my ongoing selves in those ways, that makes that possible.

Again, a paradoxical move. You know, like moving to be living alone could be seen as more individualistic in a way, but to me it's like a step towards a much more collective way of living and relating. But it's almost like the first stage that's necessary. Like if we've been indoctrinated in all these ways, there's a process of unlearning that needs to happen before you can have enough space, and clarity, and enough capacity for something quite different. And I feel like that's where I'm at the moment in terms of work and home and relationships. So it's 
almost a bit like going on retreat to really unpack where you've got to, to really see yourself very clearly and to practice different ways of being.

It's very much like a daily practice of slowing right down and noticing what I do to myself, where that comes from in terms of that wider non-consensual capitalist culture, learning to do that differently and then being alongside other people who are trying to do that same kind of work, and then working with them about how could we co create something different. And my sense is that it can probably only happen on quite a small scale: a ground-up way of us to be radically different. Maybe it's not even possible, but I'm interested in playing with that space, you know? For me, it felt like being outside of academia and outside of certain conventions around how to live and relate and do home and do work, was necessary to be able to do the next phase of what I wanted to be doing. Watch this space as to how that proceeds.

D: Is there anything else you'd like to add or say or reflect on the experience of the interview itself, maybe?

MJ: It's funny to be answering these questions. I definitely notice there's still an imagined academic that I'm viewing myself through, and that can critically respond to everything I've said, you know? I just know how they could dismantle everything I've said and I feel some sadness for the way that's so much part of it all... the ways that academia probably does nourish, in a very negative way, people's inner critics and outer critics. We're encouraged to be critical.

I love being critical in one way as in having that kind of criticality about normativities and systems and structures of power. But the criticising of people and of ourselves, I think it's just so rampant. And I think it's really telling that even during this interview I'm like "oh, I can't mention that theory because it will just be looked down on". So many things I've said, I can just hear people say "how overly simplistic that is" or that you're falling back into a binary there, or, you know...? [both laugh] Yeah, there's almost a question of why do this? Why put this out there for people to just... How might people read this? Do I want to put something out that people could read and be dismissive in those ways that are very familiar to me? And then, do I care? Like, it might be "what the hell, put it out there." And then kind of "oh, actually some people might read this who are exactly needing this kind of thing right now and it will be refreshing to them", which is often what's happened when I have written about this kind of stuff. So I'm really grateful for the opportunity and really fascinated in what it invokes in me. 
And how has it been doing the interview for you? You're in and I'm out of there, how does that feel? [both laugh]

Meg-John Barker is the author of a number of popular books on sex, gender, and relationships, including Queer: A Graphic History, Gender: A Graphic Guide, How To Understand Your Gender, Life Isn't Binary, Enjoy Sex (How, When, and IF You Want To), Rewriting the Rules, The Psychology of Sex, and The Secrets of Enduring Love. They have also written a number of books for scholars and counsellors on these topics, drawing on their own research and therapeutic practice. Websites: rewriting-the-rules.com, megjohnandjustin.com. Twitter: @megjohnbarker,Instagram:@meg_john_barker.

Daniel Cardoso (MSCFA Research Fellow) holds a PhD in Communication Sciences by the NOVA University, and is a Research Fellow at the Department of Sociology at Manchester Metropolitan University, UK, and a part of RCASS and its Gender and Sexuality Research Group. They remain associated with the LUSOFONA University, in Lisbon, where they taught for ten years. Their main areas of research are consensual non-monogamies, BDSM, gender and sexualities, young and new media, and cybercultures. Their work and activism can be found at www.danielscardoso.net

This interview was conducted during February 2020.

\section{Bibliography}

Ahmed, S. (2016). Resignation is a feminist issue. Feminist Killjoys https://feministkilljoys.com/2016/08/27/resignation-is-a-feminist-issue/

Barker, M.-J. (2019, August 28). Embracing failure in work, home, and relationships. Rewriting The Rules. https://www.rewriting-the-rules.com/self/embracing-failure-inwork-home-and-relationships/

Barker, M.-J. (2020). Plural selves, queer, and comics. Journal of Graphic Novels and Comics, 1-12. https://doi.org/10.1080/21504857.2020.1774403

Beck, U. (1992) Risk Society: Towards a New Modernity. London: Sage.

Gill, R. (2009). Secrecy, silence, toxic shame and the hidden injuries of the neo-liberal university. In R. Ryan-Flood and R. Gill (Eds). Secrecy and silence in the research process: Feminist reflections. London: Routledge, 228-244. 
Halberstam, J. (2011). The queer art of failure. Durham, North Carolina: Duke University Press.

Lorde, A. (2018). The Master's Tools Will Never Dismantle the Master's House. Penguin Classics.

Pearce, R. (2020). A Methodology for the Marginalised: Surviving Oppression and Traumatic Fieldwork in the Neoliberal Academy. Sociology, 54(4): 806-824.

Pereira, M. do M. (2017). Power, Knowledge and Feminist Scholarship: An Ethnography of Academia. Routledge.

Rose, N. (1990). Governing the soul: The shaping of the private self. London: Routledge.

Rubin, G. (2007). Thinking Sex: Notes for a radical theory of the politics of sexuality. In R. Parker \& P. Aggleton (Eds.), Culture, Society and Sexuality: A Reader (2nd ed., pp. 150-187). Routledge. 